\title{
Effect of short term changes in blood glucose on visual pathway function in insulin dependent diabetes
}

\author{
Kevin J Hardy, Mark O Scase, David H Foster, John H B Scarpello
}

\begin{abstract}
Background-Visual pathway function is abnormal in patients with insulin dependent diabetes mellitus (IDDM) without retinopathy, yet the mechanism underlying this abnormality is unknown. It is hypothesised that short term changes in blood glucose level affect visual pathway function in IDDM.

Methods-Colour discrimination was measured in 10 uncomplicated aretinopathic IDDM patients during hyperinsulinaemic clamp, with the Farnsworth Munsell 100 hue test (100 hue test). After stable euglycaemia, patients were made hyperglycaemic (14 mmol/1), maintained euglycaemic (5 $\mathrm{mmol} / \mathrm{l})$, and rendered hypoglycaemic $(2.5 \mathrm{mmol} / \mathrm{h})$, in random order, on separate occasions at least 1 week apart.

Results-Short term (1-2 hours) changes in blood glucose did not affect colour discrimination: mean (SD) 100 hue error score at $2.5 \mathrm{mmol} / \mathrm{l}$ was 34 (22) compared with 35 (33) at $5 \mathrm{mmol} / \mathrm{l}$, and 39 (28) at $14 \mathrm{mmol} / \mathrm{l}$.

Conclusion-These data suggest that short term (1-2 hours) changes in blood glucose are not the mechanism for visual pathway dysfunction in aretinopathic IDDM patients.

(Br f Ophthalmol 1995; 79: 38-41)
\end{abstract}

Visual pathway function is abnormal in most patients with uncomplicated insulin dependent diabetes mellitus (IDDM) with angiographically normal retinas. ${ }^{1}$ Increases in lens optical density sufficient to impair visual function occur early in IDDM, ${ }^{2}$ but the main site of visual pathway dysfunction is probably the retina, ${ }^{3}$ possibly at the level of the ganglion cell, ${ }^{45}$ which by virtue of its site in the retina is vulnerable to hypoxia. The presence of visual pathway dysfunction in some IDDM patients within weeks of diagnosis, ${ }^{1}$ and failure to find any correlation between visual pathway dysfunction and diabetes duration ${ }^{6}$ suggest that visual pathway dysfunction in IDDM may not be a microvascular complication. Instead, visual pathway dysfunction in aretinopathic IDDM patients may be the result of reversible changes in retinal function, perhaps secondary to some metabolic derangement of diabetes leading to, or compounded by, tissue hypoxia. Several studies have failed to show an association between retinal dysfunction and blood glucose level, ${ }^{167}$ but none was designed specifically to address this question. The aim of the present study was to test the hypothesis that visual pathway function in IDDM is affected by short term changes in blood glucose level. The results suggest that visual pathway function is unaffected by short term (1-2 hours) changes in blood glucose level (in the range $2 \cdot 5-14 \cdot 0 \mathrm{mmol} / \mathrm{l}$ ).

\section{Patients and methods}

\section{PATIENTS}

Ten patients with uncomplicated type 1 (IDDM) of mean (SD) age 28 (7) years and of diabetes duration 9 (4) years were each studied on three occasions. None of the patients had clinical evidence of microvascular complications of diabetes, including normal fluorescein angiography or fundus photography, or both, normal urinary albumin excretion rate (mean $6.6(2.8) \mu \mathrm{g} / \mathrm{min})$, and normal vibration perception. Blood pressure was also normal in every subject (mean $121 / 76 \mathrm{~mm} \mathrm{Hg}$ ). The study was approved by North Staffordshire Hospital ethics committee, and all patients gave written informed consent before being studied.

HYPERINSULINAEMIC CLAMP

A modification of the hyperinsulinaemic glucose clamp first described by DeFronzo et $a l^{8}$ was used. This method allows blood glucose to be clamped at predetermined levels while physiological measurements are made.

Briefly, after an overnight fast, patients were admitted to the metabolic unit of the North Staffordshire Royal Infirmary at 0730. Under local anaesthetic $(0.25 \mathrm{ml}$ lignocaine $2 \%$ ), an intravenous cannula (Venflon, ViggoSpectramed, Helsingborg, Sweden) was placed in an antecubital vein of the non-dominant arm. An infusion of soluble insulin (Human Actrapid, NovoNordisk, Crawley, Sussex) diluted in normal saline to a concentration of 1 unit per $\mathrm{ml}$ (with $2 \mathrm{ml}$ of the patient's blood to prevent insulin adherence to the plastic) was commenced to maintain the patient's blood glucose at approximately $5 \mathrm{mmol} / \mathrm{l}$. The infusion was adjusted every 30-60 minutes on the basis of blood glucose measurements made with a meter (Exactech, Medisense UK Inc, Harlow, Essex). The clamp was started when the patient's blood glucose had been stable at $5 \mathrm{mmol} / \mathrm{l}$ for 1 hour.

After a 10 minute priming infusion calculated according to the formula of DeFronzo, ${ }^{8}$ 


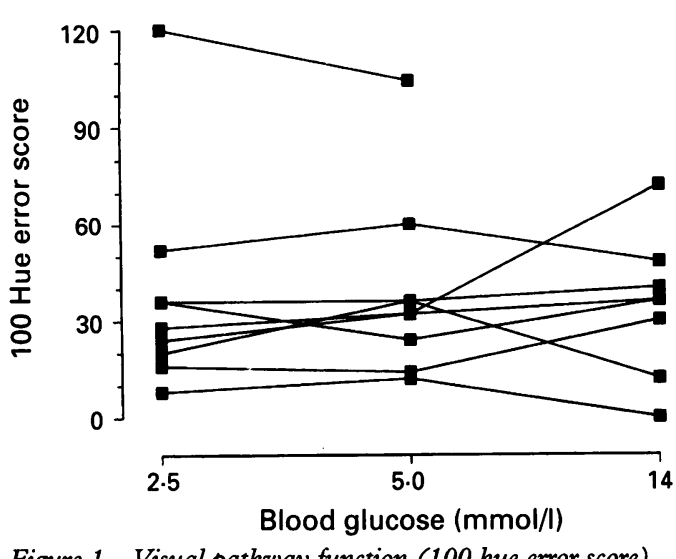

Figure 1 Visual pathway function (100 hue error score) in 10 patients with insulin dependent diabetes mellitus (IDDM) after a short term change in blood glucose from steady euglycaemia (5 mmoll) to $2 \cdot 5,5 \cdot 0$, or $14 \mathrm{mmol}$ (maintained for 1-2 hours using a hyperinsulinaemic clamp). Studies in individual patients were performed in random order, at least 1 week apart.

insulin was infused at a fixed rate of 60 $\mathrm{mU} / \mathrm{m}^{2} / \mathrm{min}$ by a syringe driver (IVAC711, IVAC Corporation, San Diego, USA) and glucose $20 \%$ at a variable rate by an Imed 960 pump (Imed, Oxford). For each study, blood glucose was raised or lowered to a predetermined level according to the experimental procedure for that day. Blood samples were obtained from a retrograde cannula in a dorsal hand vein of the same arm with the hand placed in a heated box $\left(55-60^{\circ} \mathrm{C}\right.$ ) (Hand Warming Unit DC376DJH, Nottingham University Medical Physics Department, Nottingham) to arterialise the blood. The cannula was kept patent by a slow infusion of normal saline. The glucose infusion was adjusted every 5 minutes on the basis of blood glucose measurements made with a bedside glucose oxidase method (Yellow Springs Instrument, Ohio, USA).

Mean blood glucose on admission to the metabolic unit was $5.8(2 \cdot 1) \mathrm{mmol} / \mathrm{l}$, and patients were maintained euglycaemic (mean blood glucose $5.7(0.9) \mathrm{mmol} / \mathrm{l})$ for 1 hour before the start of the clamp. During the clamp, euglycaemia (blood glucose 5.0 (0.4) $\mathrm{mmol} / \mathrm{l}$ ) was maintained for a further $76(46)$ minutes, hypoglycaemia (blood glucose $2 \cdot 5$ $(0.2) \mathrm{mmol} / \mathrm{l})$ was maintained for 54 (9) minutes, and hyperglycaemia (blood glucose $13.9(0.4) \mathrm{mmol} / \mathrm{l})$ was maintained for 119 (84) minutes. The time taken to complete the 100 hue test was similar under all three test conditions, approximately 15 minutes. One patient performed only the hypoglycaemic study, and one patient did not perform the hypoglycaemic study. The remaining patients completed all three studies.

\section{VISUAL PATHWAY FUNCTION}

Visual pathway function (colour discrimination) was measured with the Farnsworth Munsell 100 hue test (100 hue test) as described previously, ${ }^{1}$ at three different blood glucose levels chosen to encompass a range from hypoglycaemia to hyperglycaemia. Thus, on three separate occasions, at least 1 week apart, and in random order, following 1 hour of stable euglycaemia the 100 hue test was performed at a blood glucose level of either $2.5 \mathrm{mmol} / \mathrm{l}, 5 \mathrm{mmol} / \mathrm{l}$, or $14 \mathrm{mmol} / 1$. Each blood glucose level was maintained for about 1-2 hours before visual pathway function assessment, and patients were not told in which direction their blood glucose was to be changed on a particular day. The $2.5 \mathrm{mmol} / 1$ level was a compromise between achieving adequate hypoglycaemic levels and safety considerations since it was necessary to maintain subjects at hypoglycaemia for up to 1 hour. Continuous electrocardiographic monitoring and half hourly blood pressure measurements were performed during the hypoglycaemic study.

\section{STATISTICAL ANALYSIS}

Comparisons of 100 hue error scores at different blood glucose levels was by analysis of variance. Results are expressed as mean (1 SD) unless otherwise stated.

\section{Results}

Visual pathway function was unaffected by short term changes in blood glucose level: mean 100 hue error score at $2 \cdot 5,5 \cdot 0$, and 14 $\mathrm{mmol} / \mathrm{l}$ was 34 (7), 35 (11), and 39 (9), respectively, $p=0.9$. Figure 1 shows individual 100 Hue error scores for each subject during euglycaemia, hyperglycaemia, and hypoglycaemia.

\section{Discussion}

Our data suggest that visual pathway function in aretinopathic IDDM patients is not affected by short term (1-2 hours) changes in blood glucose level (in the range $2 \cdot 5-14.0 \mathrm{mmol} / \mathrm{l}$ ). This result contrasts with the findings of Harrad et al ${ }^{9}$ who showed that colour discrimination deteriorated significantly during hypoglycaemia. In their study, hypoglycaemia was more profound, reaching a mean nadir of $1.5 \mathrm{mmol} / 1$ (nearer $1 \mathrm{mmol} / 1$ in some patients). Furthermore, blood glucose during the hypoglycaemic interval was assessed by means of a glucometer which has a wide margin of error at these blood glucose levels so that some patients may have been even more profoundly hypoglycaemic. Colour discrimination impairment at a blood glucose concentration of $2.5 \mathrm{mmol} / 1$ was less than at $2.0 \mathrm{mmol} / \mathrm{l}$, and the subjects with the highest 100 hue error scores were those with the lowest blood glucose levels. It is possible that if hypoglycaemia had been more profound in our study, colour discrimination would have deteriorated, but it was considered undesirable to keep patients at such low blood glucose levels for the time necessary to perform the test. Our findings were in patients without retinopathy, so further study would be required to see if patients with established retinopathy behave similarly.

Our study has several limitations: the number of patients studied was small, though sufficient to detect a difference in 100 hue error score of 20 with a power of $0 \cdot 8$. Only one subject had a change in error score of this 
magnitude and thus there is little to suggest that testing more subjects would significantly alter our conclusions. Indeed, given the variance in colour discrimination in normal people, the 100 hue error scores at different blood glucose levels in our IDDM patients were strikingly similar. The level of hypoglycaemia $(2.5 \mathrm{mmol} / \mathrm{l})$ was modest in this study, and particularly in view of the finding of Harrad et al, ${ }^{9}$ it is likely that more severe hypoglycaemia would have produced visual pathway dysfunction.

It would be surprising in a random population of IDDM patients of mean diabetes duration of 9 (4) years to find no microvascular complications, however, the patients in the present study were specifically selected for the absence of microvascular complications after rigorous screening of our entire clinic population.

Relatively little is known about mechanisms of visual dysfunction in diabetes, or processes leading to the development of overt retinopathy, or whether the two are related. Impaired visual pathway function might be the result of preretinal factors, impeding passage of light to the photoreceptors, osmotic distortion of the retina, disrupting normal retinal topography, osmotic distortion at a cellular level (the sorbitol hypothesis), or metabolic abnormalities disrupting normal cell function.

If insufficient light were to reach the photoreceptors, visual function would be impaired. It has been suggested that abnormal increases in lens optical density might be the sole cause of visual dysfunction in diabetes. Although such an increase in lens optical density occurs early in IDDM, ${ }^{2}$ it is not the sole cause of visual dysfunction. ${ }^{3}$ Impairment of visual function might result if fluid shifts in the retina were to distort photoreceptors or their neural connections in the same way that acute changes in blood glucose lead to refractive errors secondary to osmotic distortion of the lens. ${ }^{10}$ This hypothesis would be supported by changes in visual pathway function with acute changes in blood glucose level. No such changes were evident in this study, where marked changes in blood glucose level did not affect colour discrimination.

Accumulation of osmotically active polyols may lead to dysfunction of cells in the visual pathway (osmotic hypothesis). In the alloxan diabetic rabbit, sorbitol accumulates in all layers of the retina after 17 days of diabetes, ${ }^{11}$ but the functional significance of these findings is unknown. In a 1 year, randomised, placebo controlled study of 41 diabetic patients, treatment with the aldose reductase inhibitor ponalrestat did not improve visual dysfunction. ${ }^{12}$

Activation of the polyol pathway is accompanied by a reduction in cellular myoinositol levels with reduction in sodium potassium ATPase activity, increased intracellular sodium, and impaired production of cellular secondary messengers and it may be relevant that supplementation with myoinositol normalises glucose induced increases in vascular flow and permeability. ${ }^{13}$ It has been proposed that ischaemia of the inner retina may lead to the release of the excitatory transmitters, glutamate and aspartate, with subsequent depolarisation and eventual destruction of neuronal elements, but Marano and Matschinsky have suggested that accentuated release of these neurotransmitters could just as easily be a consequence of polyol accumulation, myoinositol depletion, or concomitant changes in ion homeostasis. ${ }^{14}$

Non-enzymatic glycosylation of proteins has been implicated in the disruption of enzyme function, extracellular matrix biochemistry, transport protein properties, and the permeability characteristics of many tissues affected by diabetes, and occurs at higher rates in diabetic patients with retinopathy. ${ }^{15}$ Evidence for or against a direct role in the aetiology of visual dysfunction, however, is lacking.

Discussion of visual pathway function in diabetes is usually focused on the retina, yet, it may be that abnormalities of higher cerebral function are also important, particularly during moderate or severe hypoglycaemia. In their study, Harrad et al ${ }^{9}$ attempted to control for hypoglycaemia induced changes in higher cerebral function by asking patients to perform a psychometric test (digit span) during hypoglycaemia. They demonstrated abnormalities in colour discrimination without abnormalities in psychometric testing and concluded that colour discrimination impairment probably arose from abnormalities in the retina. It should be noted, however, that digit span is a very crude test of higher cerebral function and other authors have demonstrated a range of abnormalities in higher cerebral function during hypoglycaemia. ${ }^{16}$

Thus, this study supports the view that short term (1-2 hours) changes in blood glucose level do not account for visual dysfunction in 'uncomplicated' diabetic patients and suggests a need for further investigation of the role of changes in intermediary metabolism in the visual dysfunction of early IDDM.

We thank Mr J Bicknell of the Department of Chemica Pathology at the North Staffs Royal Infirmary for his technical assistance, and Professor Ian MacDonald of the Department of Physiology and Pharmacology, University of Nottingham School of Medicine for his guidance on glucose clamp techniques. This work was supported by a grant from Scotia Pharmaceuticals Ltd, Woodbridge Meadows, Guildford, Surrey.

1 Hardy KJ, Lipton J, Scase MO, Foster DH, Scarpello JHB Detection of colour vision abnormalities in uncomplicated type 1 diabetic patients with angiographically normal retinas. $B r$ F Ophthalmol 1992; 76: 461-4.

2 Lutze M, Bresnick GH. Lenses of diabetic patients 'yellow' at an accelerated rate similar to older normals. Invest at an accelerated rate similar to

3 Hardy KJ, Scarpello JHB. What is the effect of lens yellowing on colour discrimination in diabetics without retinopathy? Diabetic Med 1992; 9 (suppl 1): 42A

4 Bresnick GH, Condit RS, Palta M, Korth K, Groo A Syrjala S. Association of hue discrimination loss and diabetic retinopathy. Arch Ophthalmol 1985; 103: 1317-24.

5 Juen S, Kieselbach GF. Electrophysiological changes in diabetics without retinopathy. Arch Ophthalmol 1990; 108: $372-5$

6 Roy MS, Gunkel RD, Podgor MJ. Color vision defects in early diabetic retinopathy. Arch Ophthalmol 1986; 104 $225-8$.

7 Algan M, Ziegler O, Gehin P, Got I, Raspiller A, Weber M, et al. Visual evoked potentials in diabetic patients. Diabetes Care 1989; 12: 227-9.

8 DeFronzo RA, Tobin JD, Andres R. Glucose clamp technique: a method for quantifying insulin secretion and resistance. Am f Physiol 1979; 237: E214-23. 
9 Harrad RA, Cockram CS, Plumb AP, Stone S, Fenwick P, Sonksen PH. The effect of hypoglycaemia on visual funcSonksen tion: a clinical and

10 Duke-Elder WS. Changes in refraction in diabetes mellitus. Br f Ophthalmol 1925; 9: 167-87.

11 MacGregor LC, Rosecan LR, Laties AM, Matschinsky FM. Altered retinal metabolism in diabetes. I. Microanalysis of lipid, glucose, sorbitol, and myo-inositol in the choroid and in the individual layers of the rabbit retina. $\mathcal{F}$ Bio Chem 1986; 261: 4046-51.

12 Midena E, Segato T, Radin S, Fedele D, Crepaldi G. Retinal and visual function in diabetics with background retinopathy treated with ponalrestat, an aldose reductase inhibitor. Invest Ophthalmol Vis Sci 1991; 32: reductas
13 Williamson JR, Chang K, Ostrow E, Timm V, Allison W. Normalization of D-glucose-induced increases in blood flow (BF) and ${ }^{125} \mathrm{I}$-albumin permeation (Iap) by myoinositol (MI) and by pyruvate. Diabetes 1988; 37 (suppl 1): $95 \mathrm{~A}$.

14 Marano CW, Matschinsky FM. Biochemical manifestation of diabetes mellitus in microscopic layers of the cornea of diabetes mellitus in microscopic layers of

15 Monnier VM, Elmets CA, Frank KE, Vishwanath V, Yamashita T. Age-related normalization of the browning rate of collagen in diabetic subjects without retinopathy. $\mathscr{F}$ Clin Invest 1986; 78: 832-5.

16 Mitrakou A, Ryan C, Venemen T, Mokan M, Jenssen T, Kiss I, et al. Hierarchy of glycemic thresholds for activation of counterregulatory hormone secretion, initiation of symptoms and onset of cerebral dysfunction in normal humans. Am F Physiol 1991; 260: E64-7.

\section{History of ophthalmology}

\section{One of the earliest ophthalmologists}

The question 'who were the very first ophthalmologists?' is interesting, but difficult to ascertain. We know that in the fourth century BC, ophthalmology was a recognised specialty at Alexandria, and even before that Hippocrates commented on trichiasis and ocular anatomy. However, little information survives.

But around $\mathrm{AD} 800$, Hunain Is Haq lived and practised and, by amazing good fortune, much knowledge about him has survived. Enough, at least, for us to confidently label him an 'ophthalmologist'.

Hunain lived in Mesopotamia, where the ruling caliphs tended to be patrons of the arts. However, in Hunain's time, El Ma'amoun took a particular interest in Greek medicine. Hunain's father was an apothecary, and being inclined towards medicine, Hunain studied at the Persian Syrian medical school, where he perfected his Greek in order to learn directly from the texts of Galen.

He became apprenticed to El Ma'amoun's physician, graduating to the appointment of superintendent of the House of Wisdom (library). Here he had access to most of Galen's work. He translated these into Arabic, and consolidated his interest in ophthalmology.

From then, Hunain passed his years in academic study, translation, and in ophthalmic practice, learning which treatments improved his patients and which did not. In later life, pulling together the threads of his study and practical experience, he wrote 'The ten treatises on the eye', the best known of his many publications.

This was a systematic and practical ophthalmic textbook, beginning with chapters on the anatomy of the eye and ophthalmic nerves. As natural and malign 'humours' were supposed to flow along paths between the organs, the latter term would have different significance and importance than in our texts. Drugs and treatment according to Galen were described. Diseases of the membranes of the eye were covered in depth, and symptoms of conjunctival disorder. Hunain clearly recognised pannus, though calling it 'kirsophthalmos'. The latter chapters informed the students who came after him about simple remedies and detailed operative techniques for couching. Last came a comprehensive list of ophthalmic prescriptions, which doubtless were discussed, altered, and subjected to trial by each generation of physicians that followed.

Details of Hunain's daily life are preserved: academic study and clinical practice were balanced by time for a daily ride, a Turkish bath, and a short nap. Discussion with colleagues took place over cake and wine, and Hunain dined on chicken and bread and enjoyed half a measure of old wine daily. Many an overworked modern practitioner could not wish for more.

Although blessed in his lifestyle and library facilities, Hunain's work was disrupted by problems peculiar to his time. Conflict arose when his employer, the caliph, ordered him to actions incompatible with his Hippocratic oath (the poisoning of an inconvenient courtier). Losing his temper, the caliph imprisoned him for a year. But when Hunain refused again, under threat of death, the caliph gave up on the project and allowed him to return to work.

A few years later, religious conflict occurred as the Muslim caliphs denounced all other faiths. Hunain's study was disrupted again as he was hauled out of his library, made to spit on the Virgin's statue, and re-imprisoned.

The story of how these details survived sheds light on how famous an ophthalmologist Hunain was. Hirschberg investigated Arabian ophthalmology and found a plethora of Arabic and Persian texts referring heavily to Hunain, almost in the vein in which physics texts refer to Einstein today. In his search for Hunain, he then found Latin translations of the 'Ten treatises' printed in Lyons and Venice in 1515 and 1541 respectively. This implies that Hunain's book was still a standard text, so many centuries later! Hirschberg also noted that both translators independently claimed the work as their own!

The whole manuscript of Hunain's textbook was rediscovered this century, by Meyerhof, in both the library of Gregory the IVth in St Petersburg, and the library of Taimur Pasha in Egypt.

FIONA ROMAN

Cumston CG. Historical summary of the treatment of trachoma with special reference to the Arabian school. Annals of the History of Medicine 1921; 23: 244-51.

MacCallan AF. The birth of ophthalmology. Br $\mathcal{f}$ Ophthalmol 1927; 11: $66-78$.

MacCallan AF. Medieval ophthalmology in Mesopotamia. Br f Ophthalmol 1930; 14: 506-12. 